\title{
Proactive Personality and Career Success: A Person-organization Fit Perspective
}

\author{
Bo SUN ${ }^{1, a}$, Zi-Jing ZENG ${ }^{2, b, *}$ \\ ${ }^{1}$ Full Department of Scientific Research, Guangdong University of Foreign Studies, Guangzhou, \\ 510420, China \\ 2 School of Management, Guangdong University of Foreign Studies, Guangzhou, 510006, China \\ asbgz168@gdufs.edu.cn, b152188291123@163.com \\ ${ }^{*}$ Corresponding author
}

Keywords: proactive personality, PPS, career success, Person-Organization Fit

\begin{abstract}
Drawing upon the prior Person-Organization Fit literature, this paper reviews the conceptualization and measurement of both proactive personality and career success, and furthermore analyzes the integrative model of them from person-organization fit perspective. Finally, this article maps out future research should be more sensitive to how people achieve great career success by combining situational factors with individual personalities, and replenishes the literature of proactive personality with added moderators and mediators.
\end{abstract}

\section{Introduction}

Organizations increasingly expect employees to fix things that they see as wrong, act on the information they have, and react to unusual circumstances by demonstrating proactive behaviors [1] Whereas in the previous decades organizations hired employees to perform strictly defined jobs, today organizations are more likely to treat proactive behaviors as a role requirement, hire employees with a proactive orientation, and communicate to employees that proactive behaviors are valued [2]. Proactive personality is one of the motivators of proactive behaviors in the workplace [1].And there are more and more research evidences show that proactive personality is related to career benefits, which encourages organizations in favor of proactive employees. However, benefits from proactive personality are not always created, which is just like what Campbell (2000) labeled as the "initiative paradox." Make sure to achieve maximum benefits from proactive personality, it is very necessary to consider not only the employees to be proactive, but also the situational factor affecting the employees' performance. Research had contended that by having high fit with the organization (P-O fit), proactive persons can bring their attempts successfully to conclusion and follow agendas that benefit the organization, leading to greater satisfaction with jobs and careers[1].

\section{Literature Review}

\section{Proactive Personality and Career success}

\section{The Construct and Measurement of Proactive Personality}

In1993, Bateman and Crant introduced the proactive disposition as a construct that identifies differences among people in the extent to which they take action to influence their environments. Consist with the broad perspective of interactionism, they defined the prototypical proactive personality as someone who is relatively unconstrained by situational forces and who effects environmental change ,and also showed that proactive people scan for opportunities, show initiative, take action, and persevere until they reach closure by bringing about change. However, people who 
are not proactive exhibit the opposite patterns, they fail to identify, let alone seize, opportunities to change things. They show little initiative, and rely on others to be forces for change. They passively adapt to, and even endure, their circumstances [3].

Crant (2000) reviewed a number of empirical studies that show that proactive personality and proactive behavior are important for the effectiveness of individuals, teams, and organizations. Besides, the proactive personality construct was found to be positively related to extraversion, conscientiousness, need for achievement, and need for dominance, while unrelated to openness, neuroticism, agreeableness, locus of control, mental ability, and response bias [4]

Bateman and Crant (1993) had measured proactive personality construct by the 17-item proactive personality scale (PPS), using a seven-point Likert scale, with $7=$ extremely proactive to $1=$ not at all proactive. In view of the increasing multicultural context of proactive personality and proactive behavior for effectiveness of individuals, teams, and organizations, Claes, Beheydt and Lemmens(2005) investigated the unidimensionality of abbreviated forms of the PPS (with 10, 6, 5, and 4 items) selected from the PPS (17items)by Bateman and Crant (1993).Results showed that the 6-item PPS, measured the proactive personality in an internally consistent manner and through a single factor, and a one-factor solution for the 10-item PPS was a suboptimal solution[5].

\section{The Construct and Measurement of Career Success}

Career success is a concern issue to both individuals and organizations, which dues to employees' personal success eventually contributing to organizational success. Consequently, career success has aroused great interest in career scholars who have tried to combine the individual factors with the organizational ones to promote employees' career success (e.g., [6, 7])

Career success is defined as the accumulated positive work and psychological outcomes resulting from one's work experiences [7]. The measurement of career success includes objective or extrinsic and subjective or intrinsic career success career success. Salary [8] and salary growth [9] are the most widely used and readily accessible indicators of career success [10,11]. These objective measures can have the substantial benefits of being readily available from existing records, standardized (at least within firms), and efficient to collect. They are free from self-serving and common-method variance, if collected by means other than self-report [12]. However, the deficiency of traditional objective criteria, such as pay and promotions, stems from the fact that these are not the only objective outcomes that people seek from their careers [12]. Therefore, the potential deficiencies in objective success measurement may be reduced by combining subjective career success with objective attainments.

Subjective career success is defined by an individual's reactions to his or her unfolding career experiences [13, 14]. Recognition of the importance of subjective success dates back at least to Thorndike's (1934) operationalization of career success as job satisfaction, as well as the objective criteria of earnings and job status[12] Although objective criteria have dominated much of the subsequent career success literature, subjective criteria have increasingly been adopted within career success research over the last decade[11,15].

\section{Relationships Between Proactive Personality and Career Success}

Identification of variables influencing career success has received considerable research attention from organizational scholars [16]. Seibert, Crant \& Kraimer (1999) examined the relationship between proactive personality and career success by surveying a sample of 496 employees (320 men and 176 women) from a diverse set of occupations and organizations. Proactive personality was positively associated with both self-reported objective (salary and promotions) and subjective (career satisfaction) indicators of career success. They thought that proactive individuals approach their jobs and careers differently than less proactive people [6]. 
In 2001, Seibert, Crant \& Kraimer furthermore developed and tested a model linking proactive personality and career success through a set of four behavioral and cognitive mediators. They used a 2-year longitudinal design with data from a sample of 180 fulltime employees and their supervisors, which had results showed that proactive personality was positively related to innovation, political knowledge, and career initiative, but not voice, Innovation, political knowledge, and career initiative in turn had positive relationships with career progression (salary growth and the number of promotions during the previous 2 years) and career satisfaction. However, voice had a negative relationship with career progression [7].

Bertolino, Truxillo\& Fraccaroli (2011) had investigated whether age would moderate the relationship between proactive personality and three training-related variables: training motivation, perceived career development from training, and training behavioral intentions. Results had showed that participants' age moderated the relationship between proactive personality and these outcomes. Specifically, there was generally a more positive relationship between proactive personality and the outcomes for younger participants than for older participants [17].

A model of relationships between proactive personality and career success as follows:

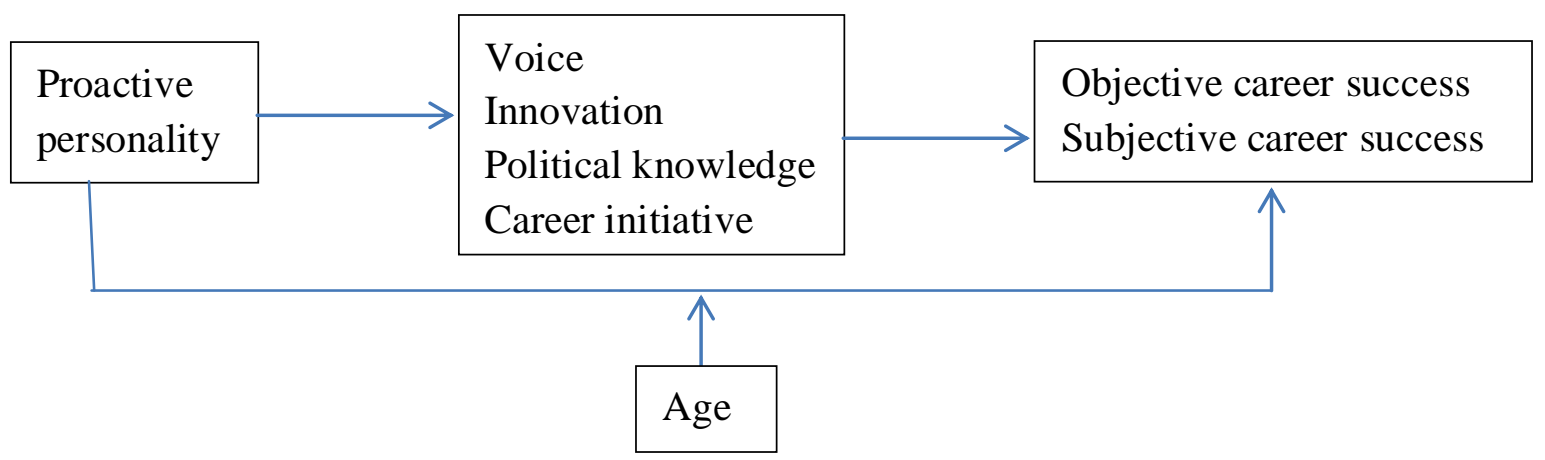

Fig. 1 A model of relationships between proactive personality and career success

\section{Person-organization Fit}

Person-organization (P-0) fit has aroused the attention of both scholars and managers for many years. Drawing on the P-0 fit literature have had, Kristof (1996) defined P-0 fit as the "compatibility between people and the organizations in which they work" by integrating its various conceptualizations, operationalizations or measurement strategies [19]. Despite the general consensus that PO fit involves the compatibility between individuals and their organizations, the definition of P-0 fit has been subject to confusion due to its multiple conceptualizations and operationalizations, as well as its limited distinction from other forms of P-E fit[16,18].

P-0 fit has been defined in a variety of ways including value congruence, work environment congruence, needs-supplies fit and demands-abilities fit $[19,20]$. Value congruence, the most frequently assessed dimension of PO fit, involves the similarity between organizational values and those of the organization's employees [19].

In an integrative review of the P-0 fit literature, Kristof (1996) classified differences in the measurement of P-O fit into three categories: subjective fit, perceived fit, and objective fit. The primary commonality between these approaches is that all three assess discrepancies between the characteristics of an individual and the characteristics of the organization.

Subjective fit measures involve directly asking an individual how well their characteristics fit with their employing organization's characteristics [21]. Perceived fit measures ask individuals to describe themselves, as well as their perceptions of organizational characteristics. The degree of fit 
is then calculated by assessing the discrepancy between a respondent's self-description and that same respondent's description [21]. Both perceived and subjective fit measures may be contrasted with objective fit measures, which ask an individual to describe his or her own characteristics, and then ask other organizational members to describe the characteristics of the organization [21].

\section{A Meta-analysis of Proactive Personality and Career Success from Person-organization Fit Perspective}

Like all behavior, proactive behavior has both personal and situational causes [22]. Proactive personality, as an individual disposition, is a stable disposition to proactive behavior. Employees with proactive personalities use initiative, persevere, and attempt to shape their environment [3]. At the same time, proactive behavior will seek the balance with situational factors to achieve behavioral outcomes. Still, the emphasis in the career choice literature on a match between the person and the job, organization, or occupation had suggested an important role for situational moderators of the personality-career success relationship [7].

However, there is also anecdotal evidence suggesting that proactive persons may engage in misguided behaviors, costing organizations time and money [2]. Proactive individuals may sometimes receive no career benefits for their actions, and their behaviors may not align with organizational goals. To aid selection and career planning, identifying the conditions under which proactive personality is related to outcomes such as experienced career success is critical [1]. Therefore, research on proactive personality and career benefits needs to take P-O fit into consideration.

In assessing supplementary fit, personality has also been adopted into the domains of P-O fit. Chatman (1991) argued for values as the basis of P-O fit because values are enduring characteristics of individuals and organizations [23]. Yet, Ryan and Kristof-Brown (2003) suggested that personality traits are more stable, proximal to behavior, and visible in others' behavior than are value [24]. Therefore, when obtaining behavioral outcomes, there should be considering dispositional and situational factors, that is to say, proactive personality, as an individual disposition, will facilitate great achievements with P-O fit. Proactive personality can be advantageous for one's career, as it is related to performance [25], extrinsic as well as intrinsic career success [6, 7].

Erdogan and Baue(2005)had examined person-organization fit (P-O fit) and person-job fit (P-J fit) as moderators of the relationship between proactive personality and intrinsic career success ( job and career satisfaction).They hypothesized that proactive personality would be related to intrinsic career success only to the extent that individuals had high fit with organizations and jobs. Using a sample of 295 teachers and 139 of their peers working in 15 elementary and high schools in Turkey, they found that proactive personality was positively related to job satisfaction only for individuals with high $\mathrm{P}-\mathrm{O}$ fit. Furthermore, proactive personality was positively related to career satisfaction only for individuals with high $\mathrm{P}-\mathrm{O}$ fit. They replicated the findings for $\mathrm{P}-\mathrm{O}$ fit as a moderator of personality with respect to job and career satisfaction with a sample of 203 university professors in the United States [1].

\section{Conclusions and Future research}

In conclusion, this study reviews the relationship between proactive personality and career success under which proactive person is well-matched with organization. Organizations may obtain the career benefits from proactive personality by ensuring that proactive individuals have high levels of $\mathrm{P}-\mathrm{O}$ fit and mediating by voice, innovation, political knowledge, career initiative. 
Considering the significance of proactive personality and P-O fit theory on the behavioral outcomes in the organization, there are two suggestions for future research.

Firstly, future research may benefit from the proactive personality by considering other moderators and mediators from $\mathrm{P}-\mathrm{O}$ fit perspective. Organizational culture and organizational structure, for instance, may act as moderators of proactive personality [1]. In highly bureaucratic organizations or those organizations where deviating from rules have serious consequences (such as nuclear power plant operators, nurses, and air traffic controllers), proactive personality can be an undesirable trait [1]. Campbell (2000) had also discussed other characteristics of effective proactive individuals, providing a rationale for other moderators and mediators [2].

Secondly, the measurement of P-O fit also needs to be fitting with the types of organization. Different organization types may consider different indicators or integrate all the indicators. As P-0 fit becomes a more popular topic with both researchers and managers, increased attention must be paid to its multiple conceptualizations and measurement strategies. Only when these issues have been attended to can researchers draw convincing conclusions concerning the consequences of fit for individuals and organizations [19].

\section{Acknowledgement}

This research was financially supported by the Cloud Computing and Human Resource Service Platform of Small and Medium-size Enterprises, 2012B091100490, the Research on the Development of Science and Technology Intermediary Service Institutions Based on the perspective of Financial Support, 2011B040400014.

\section{References}

[1] B. Erdogan, T. N. Bauer, Enhancing career benefits of employee proactive personality: The role of fit with jobs and organizations. Personnel Psychology, 58(2005)859-891.

[2] D.J. Campbell, The proactive employee: Managing workplace initiative. Academy of Management Executive, 14 (2000) 52-66.

[3] T. S. Bateman, J.M. Crant, The proactive component of organizational-behavior: A measure and correlates. Journal of Organizational Behavior, 14(1993) 103-118.

[4] J. M. Crant, Proactive behavior in organizations. Journal of Management, 26(2000)435-462.

[5] R. Claes, C. Beheydt \& B. Lemmens, Unidimensionality of abbreviated proactive personality scales across cultures. Applied Psychology: an international review, 54(2005) 476-489.

[6] S. E. Seibert, J.M. Crant, Kraimer, M L. Proactive personality and career success Journal of Applied Psychology, 1999, 84: 416-427.

[7] S. E. Seibert, M. L. Kraimer \&J. M. Crant, What do proactive people do? A longitudinal model linking proactive personality and career success. Personnel Psychology, 54(2001)845-874.

[8] E. L. Thorndike, Prediction of vocational success. New York: Oxford University Press, 1934.

[9] T. L. Hilton, W. R. Dill, Salary growth as a criterion of career progress. Journal of Applied Psychology, 46(1962), 153-158.

[10]D. T. Hall. Careers in Organizations, Glenview, IL: Scott, Foresman. 1976

[11]D. T. Hall, Careers in and out of Organizations. Thousand Oaks, CA: Sage, 2002.

[12]P. A. Heslin, Conceptualizing and evaluating career success. Journal of Organizational Behavior, 26(2005)113-136. 
[13] E. C. Hughes, Institutional office and the person. American Journal of Sociology, 43(1937)404-413.

[14]E. C. Hughes, Men and their work. Glencoe: Free Press , 1958.

[15]J. H. Greenhaus, Career Dynamics. In W. C. Borman, D. R. Ilgen, \& R. J. Klimoski (Eds.), Comprehensive handbook of psychology. Industrial and organizational psychology, New York: Wiley, 12(2003), pp. 519-540.

[16]S.L. Rynes, B. Gerhart. Interviewer assessments of applicant "fit:" An exploratory investigation. Personnel Psychology, 43(1990)13-35.

[17]M. Bertolino, D.M. Truxillo \& F. Fraccaroli, Age as moderator of the relationship of proactive personality with training motivation, perceived career development from training, and training behavioral intentions. Journal of Organizational Behavior, 32(2011) 248-263.

[18]T.A. Judge, G.R. Ferris. The elusive criterion of fit in human resource staffing decisions. Human Resource Planning, 15(1992), 47-67.

[19]A.L. Kristiof, Person-organization fit: an integrative review of its conceptualizations, measurement, and implication. Personnel Psychology, 49(1996)1-49.

[20]J.W. Westerman, L.A. Cyr, An Integrative Analysis of Person-Organization Fit Theories. International Journal of selection and assessment, 12(2004)252-261.

[21] B. J. Hoffman, D. J. Woehr, A quantitative review of the relationship between person-organization fit and behavioral outcomes. Journal of Vocational Behavior, 68 (2006)389-399.

[22]K. Lewin, The conceptual Representation and the Measurement of Psychological Forces, Duke University Press, Durham, N, C, 1938.

[23]J.A. Chatman, Matching people and organizations: Selection and socialization in public accounting firms. Administrative Science Quarterly, 36(1991) 459-484.

[24]A.M. Ryan, A. L. Kristof-Brown, Personality's role in person-organization fit: Unresolved issues. In M. Barrick, A.M. Ryan, (Eds.), Personality and work. San Francisco, CA: Jossey-Bass, 2003, pp. 262-288.

[25]J. M. Crant, The proactive personality scale and objective job performance among real estate agents. Journal of Applied Psychology, 80(1995) 532-537.

[26]A. L. Kristof-Brown, R. D. Zimmerman \& E. C. Johnson, Consequences of individuals at work: A meta-analysis of person-job, person-organization, person-group, and person-supervisor fit. Personnel Psychology, 58(2005)281-342.

[27]J. M. Crant, T. S. Bateman, Charismatic leadership viewed from above: The impact of proactive personality. Journal of Organizational Behavior, 21 (2000) 63-75.

[28]J. M. Crant, The proactive personality scale as a predictor of entrepreneurial intention. Journal of Small Business Management, 34(1996) 42-49.

[29]J.R. Edwards, Person-job fit: A conceptual integration, literature review and methodological critique. International Review of Industrial/Organizational Psychology, London: Wiley, 1991(6), pp. 283-357.

[30]R. L. Thorndike, The prediction of vocational success. Vocational Guidance Quarterly, 11(1963) 179-187.

[31]S. E. Seibert, M. L. Kraimer, The five-factor model of personality and career success. Journal of Vocational Behavior, 58(2001)1-21. 